\title{
EDUCAÇÃO AMBIENTAL CONSTRUINDO ELOS ENTRE SAÚDE E MEIO AMBIENTE: RELATO DE EXPERIÊNCIA NUMA ESCOLA PÚBLICA EM JOÃO PESSOA (PB)
}

Adjane Araújo Machado ${ }^{1}$

Resumo: $O$ presente artigo aborda o relato de práticas de Educação Ambiental, como um campo de saber que dialoga com a área da saúde, numa escola pública em João Pessoa/PB, no sentido de envolver os estudantes na preservação do ambiente escolar e, consequentemente, na garantia de uma melhor qualidade de vida para todos. A proposta metodológica é de natureza qualitativa baseada na Educação Ambiental Crítica e utilizando o método da pesquisa-ação. Destaca-se que a escola representa um espaço privilegiado para socialização de conhecimentos que incentivem a preservação do meio ambiente, o bem estar coletivo e a construção de uma sociedade mais justa e sustentável.

Palavras-chave: Educação; Meio Ambiente; Saúde. 


\section{Introdução}

A construção de um elo entre saúde e meio ambiente é facilmente estabelecida, uma vez que a garantia de uma qualidade de vida sadia pressupõe um ambiente sócio ecologicamente equilibrado. Essa inter-relação, apesar de ainda tênue na literatura (VIEIRA; OLIVEIRA, 2011), assume relevância diante do atual contexto ambiental que sinaliza a importância de um projeto de desenvolvimento mais justo e sustentável.

Nessa perspectiva, a Educação Ambiental - EA se apresenta como uma estratégia de mediação da temática, pois, além da incorporação de valores e atitudes éticas nos conhecimentos sobre os fatores ambientais (MENEGUZZO; MENEGUZZO, 2013), supõe considerar o meio ambiente como um bem coletivo e discutir as complexas relações entre natureza e sociedade (CARVALHO, 2012). Segundo Carvalho (2012) a EA tem sido uma importante prática política e pedagógica mediadora de conhecimentos que permitem produzir reflexões, concepções e experiências, que visam construir o respeito, a valoração e à proteção do meio ambiente.

Esse campo de saber, apesar de ter privilegiado, inicialmente, a aplicação da EA a partir de uma ordem ecológica, na qual predominava a ênfase nos conhecimentos biológicos relacionados à preservação das plantas, dos rios e dos animais (CARVALHO, 2012), atualmente pressupõe uma reflexão mais complexa das questões ambientais para possibilitar a compreensão dos diversos fatores que impactam positiva ou negativamente a saúde humana e a vida dos demais seres vivos.

Por esse motivo, este diálogo torna-se importante, pois o estado do meio ambiente interfere significativamente nas condições de bem-estar e/ou nas situações de riscos potenciais à saúde humana (MMA, 2002). Questões relacionadas à produção de lixo, por exemplo, representam uma das principais problemáticas em nível planetário, tanto do ponto de vista dos riscos decorrentes - desde a origem até o destino final do resíduo - quanto no âmbito dos atuais padrões de consumo da sociedade. Tal problemática desperta a importância para novas formas de pensar e agir sobre o meio ambiente, bem como, sinaliza medidas de controle para à promoção da saúde e o bem-estar ecológico e humano.

No âmbito escolar, pode-se dizer que essa também é uma das principais preocupações abordadas (FERREIRA, 2013) e a educação sanitária ${ }^{2}$ representa, muitas vezes, a base para iniciar atividades de conscientização ambiental entre os discentes, sobretudo, a partir de atividades que buscam o respeito e a preservação da natureza, tais como a coleta de lixo realizada por intermédio de passeios ecológicos. Contudo, as inter-relações entre meio

\footnotetext{
2 A educação sanitária consiste em práticas de higiene para a saúde individual e coletiva, que segundo, Mohr e Schall (1992), se inseriu no contexto escolar na metade do século XIX, com o intuito de corrigir a ignorância familiar que comprometia a saúde da criança, e foi implementada como política pública no Brasil na década de 70, na tentativa de articular saúde e educação e tornar os conhecimentos básicos de saúde e higiene uma prática obrigatória nas escolas.
}

revista brasileira educação ambiental 
ambiente e saúde ainda são pouco enfatizadas ou limitadas à apresentação simplista de conteúdos, sem abranger a complexidade da questão ambiental, social, política, econômica, cultural, ecológica e histórica.

Nesse contexto, esse artigo objetiva refletir sobre essa temática a partir do relato de experiência de práticas de $E A$, realizadas no período de 2012 a 2015, numa escola pública de ensino médio integrado ao ensino técnico, em João Pessoa/PB. A escola possui uma área total de 22 mil metros quadrados com aproximadamente 3.400 metros de área construída e a disponibilidade de espaços sem aproveitamento torna-se propícia à expansão de matagal, à atração de animais e ao acúmulo de lixo. Tal problemática urge a necessidade da adoção de medidas de controle de riscos ambientais e, para tanto, a EA se apresentou como uma alternativa de conciliar conhecimentos teóricos com ações práticas para assegurar a salubridade e garantir o equilíbrio ambiental na escola.

O artigo inicialmente aborda o tema saúde e meio ambiente a fim de debater o vínculo entre os dois campos de conhecimentos, em seguida enfoca o papel da Educação Ambiental na escola com destaque para as ações de transformação do espaço escolar. A análise qualitativa foi realizada através do método da pesquisa-ação e utilizando a técnica de entrevistas. Espera-se que este artigo possibilite a socialização de conhecimentos para o entendimento do meio ambiente, saudável e equilibrado, como um direito e dever de todos.

\section{Saúde e Meio Ambiente}

No âmago das atuais discussões sobre meio ambiente $e$ sustentabilidade, as inter-relações entre saúde humana e equilíbrio ambiental têm se tornado cada vez mais evidentes. É notório que as complexas relações da sociedade moderna vêm provocando impactos ambientais que colocam em risco a sobrevivência da humanidade e de outros seres vivos do planeta (OLIVEIRA; PIROLA; PEREIRA, 2001). A utilização predatória dos recursos naturais, a contaminação dos solos por agrotóxicos, a produtividade de sementes transgênicas, a poluição dos rios, a poluição industrial, os problemas de saneamento básico, entre outros fatores, são exemplos de impactos que têm refletido negativamente na condição de vida e de saúde do ser humano (RATTNER, 2010).

Tais questões, segundo Mohr e Schall (1992), têm também chamando a atenção para mudanças no campo da educação em saúde ${ }^{3}$ que, não se limita

\footnotetext{
${ }^{3}$ A educação em saúde compreende a integração dos conceitos e das práticas relativas à educação no âmbito da saúde, no sentido de somar saberes, produzir conhecimentos e disseminar ações que visam a prevenção da saúde individual e coletiva e a melhoria das condições de vida das populações (VER: OLIVEIRA, H. M.; GONCALVES, M. J. F. Educação em saúde: uma experiência transformadora. Revista Bras Enferm, 2004. Disponível em: < http://www.scielo.br/pdf/reben/v57n6/a28 > Acesso em: 09 de mar de 2017.)
} 
mais as práticas voltadas apenas para a higiene pública e individual, busca abranger novas perspectivas que levam em conta as relações entre ambiente físico e social. De acordo com Grynszpan (1999) o conceito de saúde limitado a visão estática da ausência de doença, não inclui o desequilíbrio social e ambiental na raiz dos problemas e cria um conflito no entendimento que os seres vivos estão inter-relacionados no meio ambiente. Por esse motivo, surge a necessidade da reconstrução do significado de bem-estar e a incorporação de um debate ético a respeito da relação do homem com a natureza (GRYNSZPAN, 1999).

Para Rattner (2010) as transformações atuais de uma economia capitalista e globalizada também exercem conexão com os problemas socioambientais e de saúde, sobretudo, no que diz respeito às populações mais carentes e excluídas do acesso aos bens econômicos, materiais e simbólicos. Segundo o autor, moradia, alimentação, emprego, saúde e educação possuem raízes sistêmicas interdependentes e a distribuição desigual de poder, dinheiro e outros recursos revela condições de vida socialmente injustas e ecologicamente insustentáveis. Desse cenário, surge, segundo o autor, a necessidade de um novo padrão de desenvolvimento, baseado na distribuição equitativa dos recursos para uma sociedade mais solidária e democrática (RATTNER, 2010).

Porto (2004) também discute essa perspectiva e afirma que, muitas das causas de doenças estão vinculadas com a parcela da população que trabalha, mora, circula e se alimenta em situações de riscos de saúde decorrentes de processos de injustiças ambientais ${ }^{4}$. Como por exemplo, moradores afetados pela poluição industrial de grandes empresas, grupos afetados por barragens de mineradoras e hidrelétricas, trabalhadores rurais atingidos por contaminação de agrotóxicos, comunidades residentes nas proximidades de depósito de lixo, entre outros (PORTO, 2004). O autor ainda acrescenta que, as dinâmicas e alterações ambientais de ordem natural - enchentes, secas, tsunamis, furacões - também provocam implicações para a saúde, principalmente, dos grupos sociais mais vulneráveis (PORTO, 2004).

A partir dos autores, percebe-se que saúde e meio ambiente são temas diretamente relacionados, bem como, entende-se a importância de pensar e discutir essa relação, a fim de conectar problemáticas antes fragmentadas em campos de saberes aparentemente distintos. Para tanto, a Educação Ambiental se apresenta como um instrumento de construção desse elo, pois de acordo com Lima (2002) a EA supõe a abordagem do meio ambiente como um bem público e o acesso a um ambiente saudável como um direito às melhores condições de vida e ao bem-estar da coletividade.

\footnotetext{
4 O termo injustiça ambiental articula a luta contra as dinâmicas discriminatórias -socioeconômicas, raciais e étnicas - com os movimentos ambientalista desenvolvidos nas últimas décadas. Sua origem se opõe ao termo justiça ambiental, entendido por um conjunto de ações e princípios para assegurar que nenhum grupo social suporte a parcela desproporcional das consequências ambientais negativas (PORTO, 2004).
}

revista brasileira educação ambiental 
Grynszpan (1999) também afirma que a melhoria da qualidade de vida é um objetivo comum da educação em saúde e da Educação Ambiental, Mohr e Schall (1992) argumentam que essa relação tem infinitas possibilidades e pode se transformar em um instrumento para construção e consolidação do exercício da cidadania. O desafio, segundo Oliveira, Pirola e Pereira (2001) é reconhecer essa dimensão na estruturação dos discursos, teorias e práticas, bem como, entender que meio ambiente e saúde estão relacionados com a cultura, a história, a geografia e a situação política da sociedade.

No que diz respeito ao contexto escolar, os Parâmetros Curriculares Nacionais - PCNs, que norteiam a estruturação dos currículos escolares e dos conteúdos mínimos a serem trabalhados no ensino fundamental, incluem a discussão dos eixos meio ambiente e saúde, como temas transversais, para a transmissão de conhecimentos que possibilitem aos discentes compreender a cidadania e o exercício dos direitos e deveres políticos, civis e sociais (MEC, 1997). Apesar de não associar diretamente as inter-relações entre os referidos temas, os PCNs estão vinculados à Lei de Diretrizes e Bases da Educação Nacional - Lei № 9.394 de 1996 - que estabelece diretrizes para as diversas modalidades de educação e ensino.

A Educação Ambiental, segundo o documento, é ressaltada como forma de "[...] contribuir para a formação de cidadãos conscientes, aptos para decidirem e atuarem na realidade socioambiental de um modo comprometido com a vida, com o bem-estar de cada um e da sociedade [...]" (MEC 1997, p. 25). Educar para a saúde refere-se ao desenvolvimento da consciência sanitária e de hábitos para uma vida saudável; envolve aspectos éticos relacionados ao direito à vida e ao direito de todos - sem discriminação - às ações de saúde pública; e inclui as relações do meio físico, social e cultural na instrumentalização de ações individuais e coletivas (MEC, 1997).

A dimensão ética ressaltada nos PCNs pode contribuir para refletir a complexa relação entre meio ambiente e saúde, sociedade e natureza, degradação e preservação, desenvolvimento e sustentabilidade. Nesse sentido, a escola torna-se um ponto de partida para discutir problemas socioambientais e refletir sobre a promoção da saúde e a qualidade de vida, sobretudo, porque atua como uma das mais importantes instituições disseminadoras de conhecimentos (TORALES, 2013).

\section{Educação Ambiental na Escola}

A escola possui um papel social de significativa relevância no processo de formação das atuais e futuras gerações, seja contribuindo no desenvolvimento cultural e científico, seja fortalecendo a formação de cidadãos responsáveis, conscientes e críticos (SEGURA, 2001; TORALES, 2013). Por esse motivo, a disseminação de conhecimentos acerca do meio ambiente, fazse necessária como forma de promover um intercâmbio de informações para construir novas visões de mundo - natural e social - e novas paisagens de vida (CARVALHO, 2012).

Revbea, São Paulo, V. 13, № 2: 264-281, 2018. 
Esse contexto torna a EA uma prática educativa inovadora, já que os espaços de relações socioambientais se diversificam, nos diferentes grupos e populações, proporcionando múltiplas visões, concepções e interesses a cerca do meio ambiente (CARVALHO, 2012). Entretanto, ao mesmo tempo, demonstra certa complexidade, pois pressupõe a integração dos espaços de dinâmicas sociais e o diálogo de saberes - cotidiano e científico -, sobretudo no universo escolar que, segundo Torales (2013), deve incorporar a dimensão de formação pedagógica, social e política.

De acordo com Segura (2001) no âmbito da escola, a EA depreende horizontes de uma educação emancipatória e uma postura crítica diante da realidade, no sentido de sensibilizar acerca do curso histórico de degradação ambiental provocada pela ação humana. Isso não que dizer, no entanto, que cabe a escola toda a responsabilidade na construção de um mundo ambientalmente saudável e equilibrado (SEGURA, 2001), mas como instituição de ensino aprendizado - planejado e sistematizado - presente num período contínuo e extenso na vida das pessoas (TORALES, 2013), a escola assume o papel de propiciar conhecimentos e subsidiar ações que visem mudanças de valores nas relações entre os seres humanos e destes com o mundo que 0 cercam (SEGURA, 2001).

A corrente da Educação Ambiental crítica - EAC, nessa perspectiva, segundo Carvalho (2012) e Guimarães (2004), propõe a politização das questões ambientais, através de processos de compreensão e intervenção, para transformação de uma realidade que se coloca num cenário de problemática socioambiental. Guimarães (2004) afirma que o objetivo da EAC é promover ambientes educativos, no qual o indivíduo possa vivenciar a construção de uma nova compreensão de mundo na relação com o coletivo, isto é, na participação do exercício da cidadania através de movimentos em conjunto, geradores de sinergias. Por esse motivo, de acordo com Carvalho (2012) a concepção ambiental pode ir além da preservação ecológica e transforma-se numa prática de interação social e relação harmoniosa.

Entretanto, pode-se dizer que EA não está efetivamente presente no cotidiano escolar e incluir suas reflexões no processo de ensino aprendizado, de forma crítica e interdisciplinar, não é uma tarefa fácil (GROHE; CORRÊA, 2012; FERREIRA, 2013). Os relatos, sobre a inserção de práticas e conteúdos teóricos de EA nas escolas, destacam dificuldades relacionadas à organização no dia a dia do ambiente escolar - inflexibilidade de horários, carga horária excessiva dos professores, etc. -, a falta de recursos para viabilizar aulas de campo, a falta de materiais pedagógicos e de apoio à formação continuada na temática, o predomínio do modelo pedagógico tradicional e a ocorrência de projetos pontuais e descontínuos, que alcançam soluções técnicas e não políticas (FERREIRA, 2013; MENEGUZZO; MENEGUZZO, 2013).

Tais dificuldades foram vivenciadas numa escola estadual de ensino médio integrado ao ensino técnico em João Pessoa, Paraíba. A escola oferece aulas integradas, no período da manhã e da tarde, com cursos profissionalizantes nas áreas de Hotelaria, Eventos, Serviço de Restaurante e

revista brasileira educação ambiental 
Bar e Informática. As primeiras ações de EA aconteceram em 2012, quando a ocorrência de casos de dengue entre professores, alunos e funcionários despertou para a necessidade de desenvolver ações de educação sanitária na escola. A problemática demandou ações emergenciais do Centro de Zoonoses e da Secretaria de Saúde do Estado para combater a proliferação do mosquito, além da urgente realização do I Mutirão de limpeza devido o grande acúmulo de resíduos nas áreas interna e externa da escola. As ações buscaram manter a salubridade ambiental e ampliar a percepção da comunidade escolar para a importância da preservação do meio ambiente como um bem coletivo.

Em 2013 a ação sanitária foi reorganizada, com a realização do ॥ Mutirão de limpeza e uma campanha de conscientização e combate à dengue. A ação mobilizou o triplo de alunos envolvidos no ano anterior, evitou a proliferação do vetor da doença e dispensou as intervenções de químicos inseticidas por parte dos órgãos de controle ambiental. Os resultados foram satisfatórios e apontaram caminhos para prosseguir com outras atividades, tais como um projeto de horta orgânica e pomar que foi implantado na escola no mesmo período. Entretanto, em 2014 a problemática de acúmulo de resíduos e o risco biológico da dengue reincidiram no cenário escolar, chamando atenção, mais uma vez, para a necessidade da realização de ações de educação sanitária na escola.

O motivo dessa reincidência foi associado com três importantes fatores: o primeiro relacionado ao fato da escola todo ano receber uma quantidade considerável de novos alunos, que repetem o descarte de resíduos de forma aleatória sem a sensibilização dos impactos ambientais e dos riscos à saúde oriundos dessa prática. O segundo associado ao baixo sentimento de pertencimento de alguns alunos veteranos, professores e funcionários, no sentido de contribuir de forma mais contínua na preservação do patrimônio ambiental escolar. E o terceiro relacionado à necessidade de uma melhor articulação entre os professores, na construção de um canal de comunicação a fim de disseminar à temática nas diversas disciplinas.

Percebeu-se então, que as ações sanitárias mesmo tendo proporcionado mudanças significativas, apresentaram resultados de curto prazo que não concretizaram mudanças de atitudes efetivas acerca da problemática ambiental na escola. Nesse contexto, foi preciso, mais uma vez, sensibilizar e mobilizar a comunidade para o III Mutirão de limpeza, ressaltando os impactos à saúde e ao meio ambiente, sobretudo, porque surgiu outro agravante biológico, com a significativa presença de roedores nas áreas sociais da escola.

Diante dessa complexidade, surgiu a ideia de continuar o projeto de Educação Ambiental e sanitária, a partir da ressignificação do espaço escolar para convivência coletiva. Para tanto, a posposta focou, além da realização do III Mutirão de limpeza, a revitalização do espaço mais arborizado da escola, no sentido de potencializar o sentimento de pertencimento, promover a mudança de atitudes para a preservação do patrimônio escolar e despertar o desenvolvimento de diferentes sociabilidades, tais como aulas extraclasses, Revbea, São Paulo, V. 13, № 2: 264-281, 2018. 
reuniões de grupos de pesquisa, atividades lúdicas, relaxamento, descontração no horário do intervalo, entre outras.

\section{Percurso Metodológico}

As ações descritas nessa pesquisa foram realizadas em 2014 com a turma do $2^{\circ}$ ano do ensino médio integrado ao curso técnico de Eventos. A escolha da turma objetivou o envolvimento dos alunos que participaram em 2013 da campanha de Educação Ambiental e sanitária na escola e a mobilização da comunidade escolar para os Mutirões de limpeza. O foco principal foi estimular a continuidade das ações que visam uma melhoria do ambiente escolar, uma vez que, a reincidência do cenário de acúmulo de resíduos na escola representou para os alunos um desestímulo a respeito da temática ambiental.

Em 2013 as ações foram interdisciplinadas com a disciplina Segurança e Higiene no Trabalho a partir da realização de vistorias para identificação de riscos ambientais e a construção de um diagnóstico ambiental da escola. Em 2014 as atividades foram interdiciplinadas com os conteúdos teóricos da disciplina de Decoração, envolvendo temas como decoração e reciclagem, revitalização de pequenos espaços, decoração verde, entre outros contextos.

Apesar do projeto ter envolvido diretamente a atuação de apenas uma turma, sua execução contou com o apoio e participação de outras turmas e professores da escola, sem o envolvimento do cumprimento de uma disciplina específica, além dos alunos que faziam parte do Grêmio Estudantil. Essa socialização foi possível com simplicidade, uma vez que atividades práticas e extraclasses são atrativas aos estudantes, por mudarem a rotina da sala de aula concentrada, na maioria das vezes, na exposição de conteúdos teóricos.

Como estratégia metodológica utilizou-se a prática pedagógica da Educação Ambiental crítica - EAC, a partir dos conceitos de Carvalho (2012), que está situada na proposta da mudança do espaço pedagógico e na integração dos problemas e dificuldades ambientais no contexto educativo. Para tanto, o projeto envolveu a técnica da observação direta, na qual os alunos realizaram vistorias para análise crítica do ambiente escolar e identificação dos potenciais espaços de riscos que poderiam ser revitalizados.

$\mathrm{Na}$ coleta de dados utilizou-se além da técnica da observação, o registro fotográfico das atividades realizadas e a aplicação de entrevistas, a partir do critério de amostragem não probabilística e intencional. Foram entrevistados alunos das turmas dos primeiros anos, por acolherem a maioria dos estudantes novatos da escola, que não haviam participado dos mutirões realizados em anos anteriores. O objetivo foi conhecer a opinião desses alunos sobre as práticas sanitárias realizadas com o intuito de melhorar o ambiente escolar e saber se os mesmos já haviam participado de uma ação semelhante.

Em função da pesquisadora fazer parte do corpo docente da escola, o projeto abarcou o método da pesquisa-ação-participativa, por envolver a 
possibilidade de transformação de uma problemática existente no cenário escolar a partir de processos abertos de prática e reflexão. Essa metodologia foi utilizada por Franco (2010), Rheinheimer e Guerra (2009), Reigada e Tozoni-Reis (2004), cujas pesquisas demonstram investigação, identificação do problema, intervenção ambiental, cooperação entre atores sociais, implementação de ações e alcance de resultados, sem seguir ordem nos procedimentos adotados, pois, segundo Toledo, Giatti e Jacobi (2014), o método da pesquisa-ação é dinâmico, aberto e flexível, permitindo novas atividades e informações sempre que necessário.

A pesquisa-ação também se revela como uma adequada proposta frente aos desafios da interdisciplinaridade, de acordo com Toledo, Giatti e Jacobi (2014), por seu potencial de desenvolver um processo de produção colaborativa de saberes, além de ser considerada uma alternativa às formas tradicionais de produção de conhecimento científico, por priorizar ação e participação dos atores envolvidos (RHEINHEIMER; GUERRA, 2009).

No contexto da Educação Ambiental, a Pesquisa-Ação Participante é ressaltada como proposta que confronta projetos limitados na disseminação de conceitos a fim de ampliar uma consciência ambiental nos indivíduos, sem envolver práticas de pessoas, em grupos sociais, que possibilitam pensar a educação como instrumento de emancipação (LOUREIRO, 2007). Nesse sentido, problematizar, agir e transformar são alicerces da metodologia que conduzem o desenvolvimento da pesquisa.

\section{Ações e Transformações}

A primeira fase para a continuidade da ação sanitária na escola consistiu na divulgação do III Mutirão Escolar, na qual os alunos do $2^{\circ}$ ano do curso de Eventos foram em todas as salas de aula sensibilizando para a importância da ação, conscientizando a respeito das doenças que podem surgir pela insalubridade do ambiente escolar e enfocando que cada um tem sua parcela de responsabilidade na preservação do meio ambiente.

Como o risco biológico da dengue apresentava-se como uma das principais problemáticas na escola, os alunos também chamaram atenção para importância de combater possíveis focos do mosquito em casa e na escola, bem como, explicaram as causas e as consequências da doença na saúde humana. Para tanto, a Secretaria de Saúde do Estado viabilizou a entrega de panfletos com informações sobre os tipos de doenças transmitidas pelo Aedes Aegypti - Dengue tipo 1, 2, 3 e 4 e Febre Chikungunya - e enfocando a eliminação da água parada como a principal precaução. Em seguida, os alunos produziram um cartaz que foi fixado no mural da escola com a seguinte frase: "III Mutirão de limpeza e combate à dengue: juntos pela proteção da saúde e pela qualidade do ambiente escolar".

Assim como nas versões anteriores, o mutirão envolveu a participação da maioria dos estudantes, além de professores e funcionários da escola (Figura 1). Diante do acúmulo e da diversidade de resíduos foi necessário Revbea, São Paulo, V. 13, № 2: 264-281, 2018. 
distribuir algumas luvas plásticas para proteção das mãos e foi exigido o uso de calça comprida, tênis e camiseta a fim de evitar acidentes. Além da coleta dos resíduos, foi realizada a higienização voluntária ${ }^{5}$ - limpeza e lavagem - de algumas salas de aula e laboratórios, bem como, a varredura geral da área, pois o acúmulo de folhas e galhos secos estava em excesso, causando o entupimento de valas e bueiros. A matéria orgânica retirada foi separada para o processo natural de degradação.

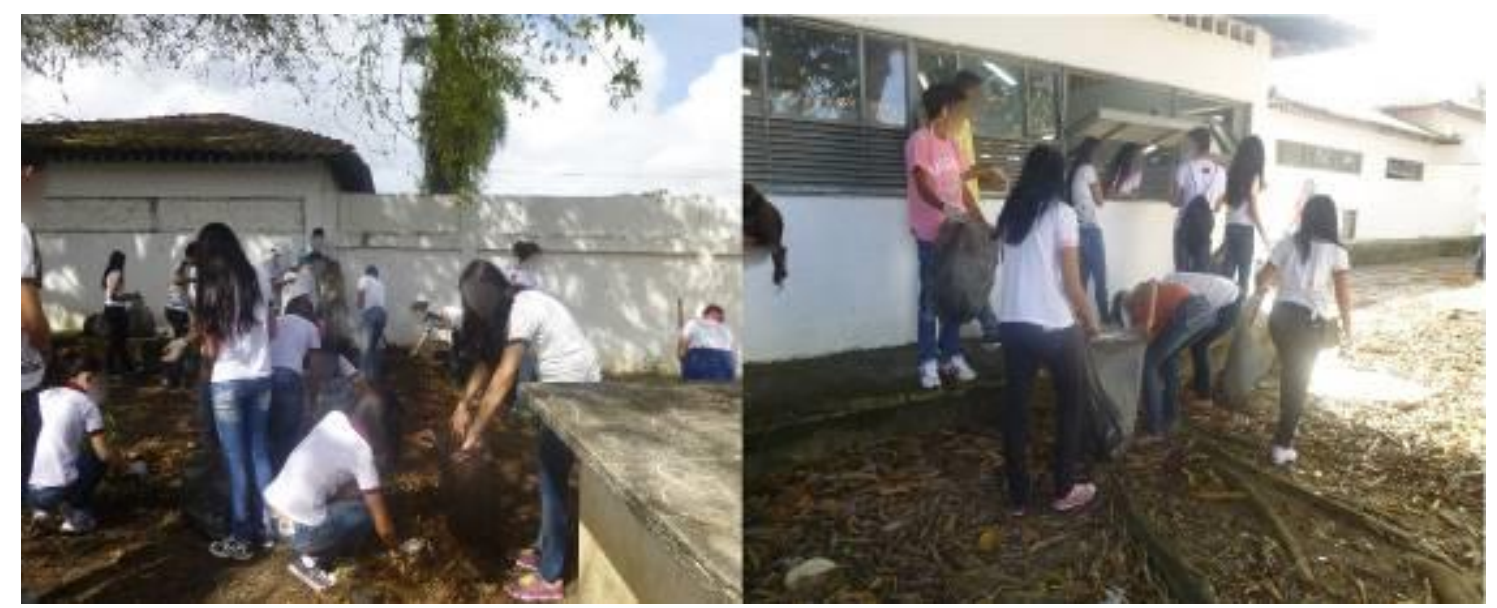

Figura 1: Imagens dos alunos no dia no mutirão escolar. Fonte: Autoria própria.

O Mutirão representou, mais uma vez, um compromisso com a promoção da saúde e com a conservação ambiental, além de uma ação reflexiva para mudar o cenário de poluição e insalubridade do espaço escolar. De acordo com Grohe e Corrêa (2012) a responsabilidade com a realidade do ambiente em que estamos inseridos é uma alternativa para mudança de pensamento a respeito da escola, do bairro e do planeta, além de estimular a consciência crítica em relação aos problemas existentes.

Vejamos o depoimento de alguns estudantes.

Foi a primeira vez que participei de um mutirão e achei a experiência bem legal, porque ensina a gente a não jogar lixo no chão. Porque o lixo que fica no chão vai acumulando água e acabar atraindo a dengue e ratos também (Aluna do $1^{\circ}$ Ano do curso de Hotelaria, 15 anos).

\footnotetext{
${ }^{5} \mathrm{~A}$ proposta do mutirão focava apenas a coleta de resíduos que comprometiam a salubridade no ambiente escolar, mas por decisão voluntária dos alunos e apoio de alguns professores os trabalhos foram ampliados, incluído outras limpezas, lavagem e varredura.
} 
Foi uma experiência muito boa, quero o ano que vem de novo, porque eu achei muito interessante os alunos limparem. Os alunos sujam e os alunos limpam. Nada mais justo. Se os alunos não sujassem não haveria o que limpar. É isso aí (Aluno do $1^{\circ}$ ano do curso de Hotelaria, 16 anos).

Na minha opinião foi legal. Foi bem interessante que eu nunca tinha feito isso. Aí veio o pessoal ajudando a limpar a escola e a preservar o meio ambiente. Achei legal e comecei a ajudar também (Aluno do $1^{\circ}$ do curso de Informática, 18 anos).

É um projeto que reuni os alunos em uma ação voluntária para que possam limpar aquilo que eles mesmos sujaram. Então, é uma ação voltada, no meu ponto de vista, para os alunos terem a consciência do que podem acontecer com as sujeiras e com os restos de plásticos que são jogados na escola (Aluno do $1^{\circ}$ ano do curso de Eventos, 15 anos).

Para a maioria dos alunos, dos primeiros anos, a participação no Mutirão representou a primeira vivência em uma atividade prática contemplando a questão sanitária e ambiental na escola. Apesar disso, percebe-se no depoimento dos estudantes que a ação foi positiva, pois despertou o senso crítico de responsabilidade com a problemática da produção de lixo e o espírito de solidariedade em torno da melhoria de qualidade do ambiente da escola. Esse fator representa uma tomada de consciência importante, pois segundo Lima (2002) a politização da problemática ambiental inicia a partir do reconhecimento do meio ambiente como um determinante para melhoria da qualidade de vida dos seres vivos e no entendimento da noção de cidadania, justiça e sustentabilidade. Além disso, Lindner (2012) acrescenta que o reconhecimento dos direitos e deveres de cada um, resgata o real compromisso da escola com a sociedade, ao formar cidadãos comprometidos com o bem comum e a coletividade.

Entretanto, apesar dos aspectos positivos mencionados, a realização de um mutirão na escola é uma tarefa que sempre provocou certos conflitos, pois todos os anos a coordenação recebe telefonemas e/ou visitas de pais de alunos expressando indignação por acharem que a limpeza do ambiente da escola é de responsabilidade dos funcionários de serviços gerais ou da Secretaria de Educação do Estado. Essa divergência chamou atenção para a necessidade de esclarecer nas reuniões dos pais a importância da realização do mutirão e convidá-los para participar do processo. Contudo, ainda há alunos que se opõem a participar da atividade e são respaldados por argumentos negativos, comuns dos padrões culturais e comportamentais da família. Esse discurso também perpassa a fala de alguns funcionários de cargos administrativos e professores, que se abstém da responsabilidade e compromisso com a preservação do ambiente escolar.

Revbea, São Paulo, V. 13, № 2: 264-281, 2018. 
Os alunos que não participaram da ação, por não concordarem com o Mutirão, também não demonstraram interesse em participar da entrevista a fim de relatar os possíveis aspectos negativos da atividade. Tal dificuldade demonstra que manter o ambiente saudável, como uma prática do dia a dia na escola, torna-se uma tarefa complexa, principalmente, diante da falta de entendimento da escola como patrimônio público que pertence a toda comunidade e, na qual, qualquer ação de depredação representa um desrespeito ao indivíduo e a coletividade. Por esse motivo, após o mutirão de limpeza, o projeto focou a revitalização do espaço mais arborizado da escola, a fim de possibilitar a construção do sentimento de pertencimento e alcançar a preservação do ambiente escolar de forma mais contínua.

O espaço revitalizado foi escolhido pelos alunos e é conhecido entre eles por "Quadrado". A área possui várias árvores sombrosas e frutíferas, permite a contemplação de um belíssimo pôr do sol e está localizada próximo ao pomar da escola. O "Quadrado" não tinha muita atratividade entre os estudantes e os poucos que frequentavam o espaço eram vistos pelos demais como aqueles que iam fumar e/ou namorar escondido, "matar" aula, pichar paredes etc. A partir da análise crítica do ambiente do "Quadrado", realizada antes e depois do Mutirão escolar, os alunos do $2^{\circ}$ ano do curso de Eventos chegaram à conclusão que o projeto de revitalização do espaço demandava uma transformação por meio das cores, uma vez que, aprenderam na disciplina de Decoração que a cores exercem influências na energia do ambiente.

Contudo, essa etapa envolvia recursos financeiros dispendiosos que não podiam ser arcados de imediato pela direção da escola. Nesse sentido, foi preciso a elaboração de um projeto para captação de recursos externos que financiassem a realização da atividade. $O$ projeto foi elaborado pela professora a partir das ideias dos alunos esclarecidas em reunião e em sala de aula. Como a proposta envolvia ações de sustentabilidade através da revitalização, o projeto recebeu em menos de dois meses a confirmação de financiamento de um hotel da cidade, que abrange ações de responsabilidade socioambiental na sua gestão empresarial.

Nesse contexto, outro mutirão foi divulgado e organizado na escola para promover a transformação do "Quadrado" com a chegada do material concedido pelo hotel. Como essa atividade demandou planejamento decorativo não foi possível envolver as 18 turmas da escola, então os alunos $2^{\circ}$ ano de eventos decidiram convidar os alunos $02^{\circ}$ ano do curso de Informática e os integrantes do Grêmio Estudantil para o trabalho de revitalização. Em questão de minutos a transformação do espaço tornou-se bastante visível, pois as cores rapidamente despertaram uma energia agradável no ambiente. Além da pintura, os alunos construíram balanços ecológicos reutilizando pneus e plantaram - em latas de alumínio e garrafas pets - algumas mudas de plantas ornamentais, doadas por um floricultor que mora nas proximidades da escola (Figura 2). 


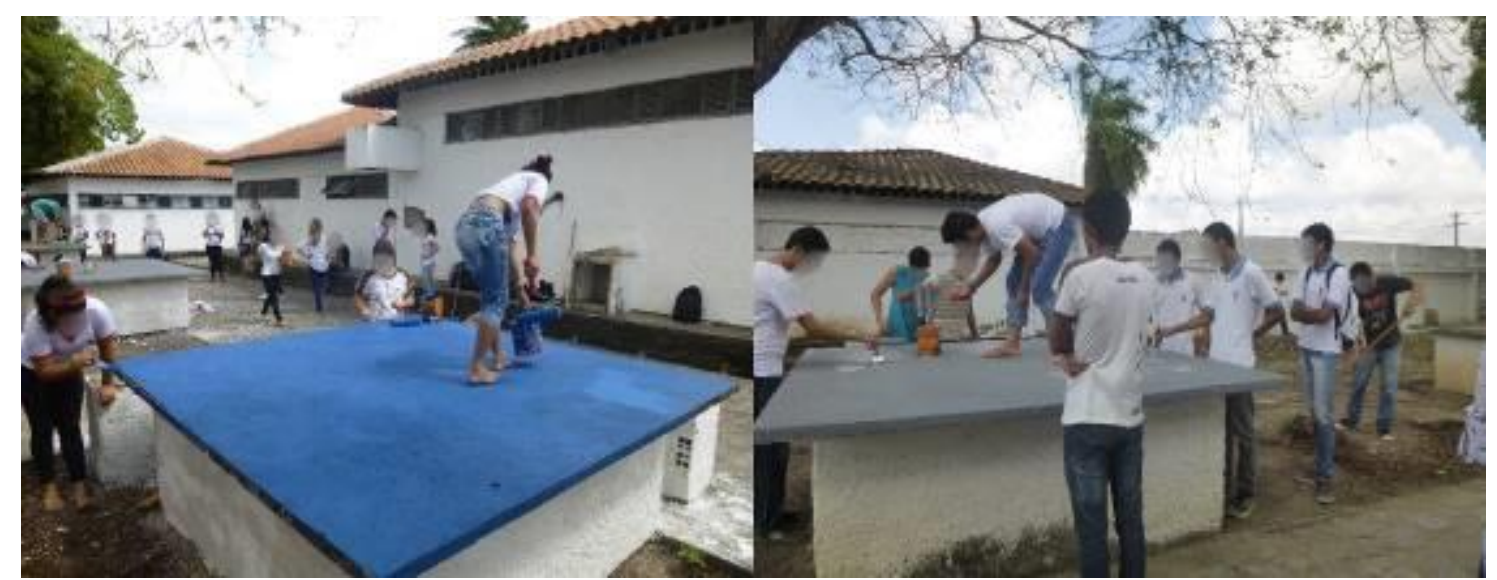

Figura 2: Imagens dos alunos no dia da pintura para a revitalização do "Quadradro".

Fonte: Autoria própria.

A atividade de revitalização do espaço incluiu ações que envolveram os alunos dentro e fora da escola, pois a coleta de garrafas pets, pneus, latas de alumínio e mudas de plantas - com os vizinhos e familiares - representou uma forma de disseminação, para outros atores sociais, da proposta de preservação ambiental e revitalização do espaço escolar. Para incentivar a proposta pedagógica, a professora solicitou ao gestor escolar a colocação de um quadro branco na área do "Quadrado", a fim de possibilitar a realização de aulas extraclasses e/ou o desenvolvimento de grupos de estudos no espaço. A revitalização foi bem aceita pela maioria dos alunos, assim como, pelos professores e funcionários.

Ficou bem melhor, antigamente a área era suja. Os alunos tiraram o matagal, fizeram a limpeza, deram uma pintada, ficou um ambiente mais agradável e ficou colorido. Fizeram balanços ecológicos que foi uma ideia muito bacana, que não precisou gastar um material caro e é uma brincadeira muito divertida. $O$ pessoal está gostando muito. [...] antigamente era só sujeira, sujeira, sujeira e o pessoal vinha aqui só para passagem mesmo (Aluno do $1^{\circ}$ Ano do curso de Informática, 15 anos).

O "Quadrado" ficou bom agora porque pintaram, botaram um balanço para a gente ficar se divertindo quando não tem o que fazer, botaram um quadro, limparam tudo [...] porque antes era muito feio, era aquele lodo não tinha nem como sentar [...] e achei bom (Aluno do $1^{\circ}$ ano do curso de Hotelaria, 15 anos).

Quando a gente fez o mutirão isso aqui estava quase abandonado, sem cor, sem vida. Agora tá uma coisa que está gerando diversão, deu uma nova cor, uma nova vida para escola. Além de que pode nos possibilitar um novo tipo de aula, que a aula extraclasse, uma coisa que só trouxe o bem (Aluno do $1^{\circ}$ ano do curso de Hotelaria, 15 anos). 
Bom, a revitalização do ambiente conhecido como "Quadrado", foi algo de muita importância, porque antes se encontrava acabado, cheio de folhas secas, também vários lixos que os próprios alunos jogaram. E eu acredito que foi uma grande ação [...] na revitalização do ambiente porque podemos usar agora até para aplicar a nossas aulas (Aluno $1^{\circ}$ ano do curso de Eventos, 16 anos).

A partir do depoimento dos estudantes, percebe-se que a revitalização promoveu a sensação de melhoramento e valorização de um espaço que anteriormente não possuía visibilidade e encontrava-se bastante ocioso (Figura 3). Tal sentimento é importante para despertar novas atitudes, ampliar visões e favorecer o relacionamento dos estudantes com a escola. Para Kindel (2012) a construção de atitudes e valores positivos é um grande desafio na educação, pois não basta trabalhar conceitos em sala de aula, é necessário despertar comportamentos que despertem a consciência ambiental no dia a dia da escola.

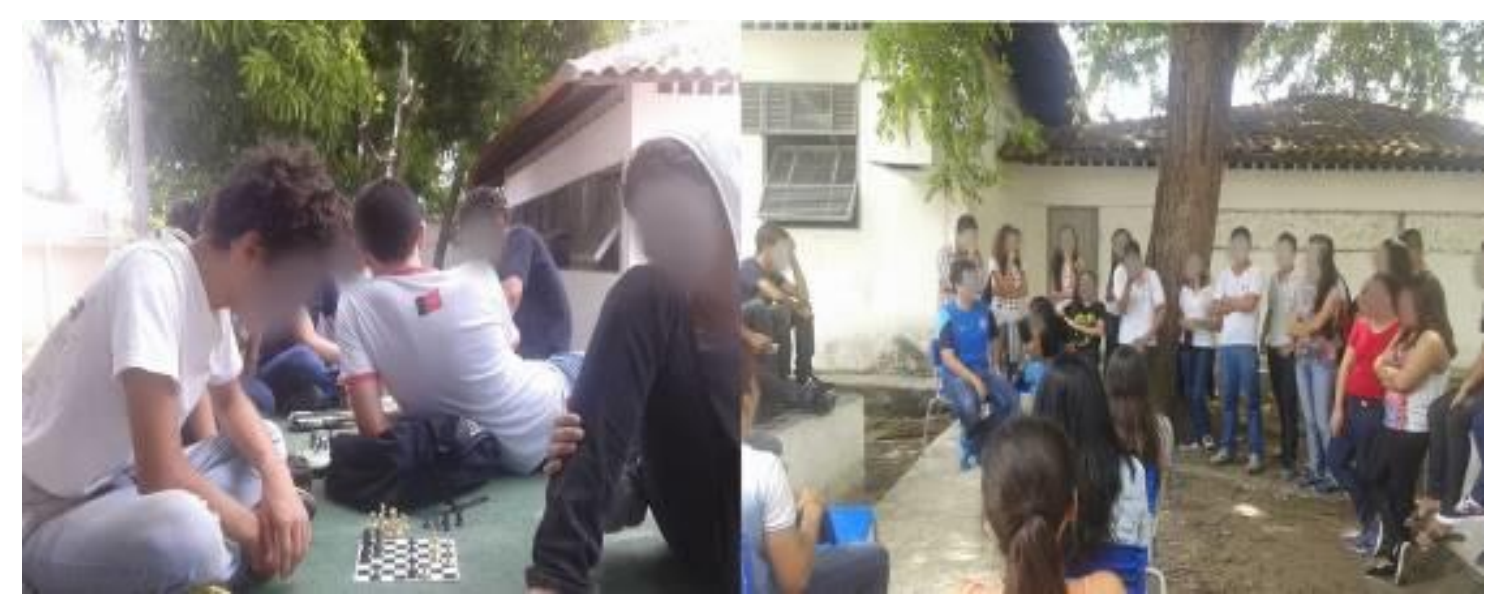

Figura 3: Imagens das novas apropriações do espaço do "Quadrado". Fonte: Autoria própria.

Como furto de novas sociabilidades, destaca-se que o "Quadrado" ganhou visibilidade como espaço de lazer, em especial pelos balanços ecológicos, jogos educativos, dinâmicas de grupo, entre outras atividades, e despertou a atenção de outros espaços da escola que também podem ser revitalizados. Essas novas apropriações incentivam a preservação do patromônio público escolar e despertam a importância da salubridade ambiental, como forma de garantir o direito de uso e o bem-estar de toda comunidade. Vale destacar ainda, que as árvores do "Quadrado" ofecerem ventilação natural, contemplação do cantar dos passáros, a observação de diversos saguins e frutas em determinadas épocas, comprovando que as áreas verdes são sempre benéficas e devem ser valorizadas (Figura 4). 


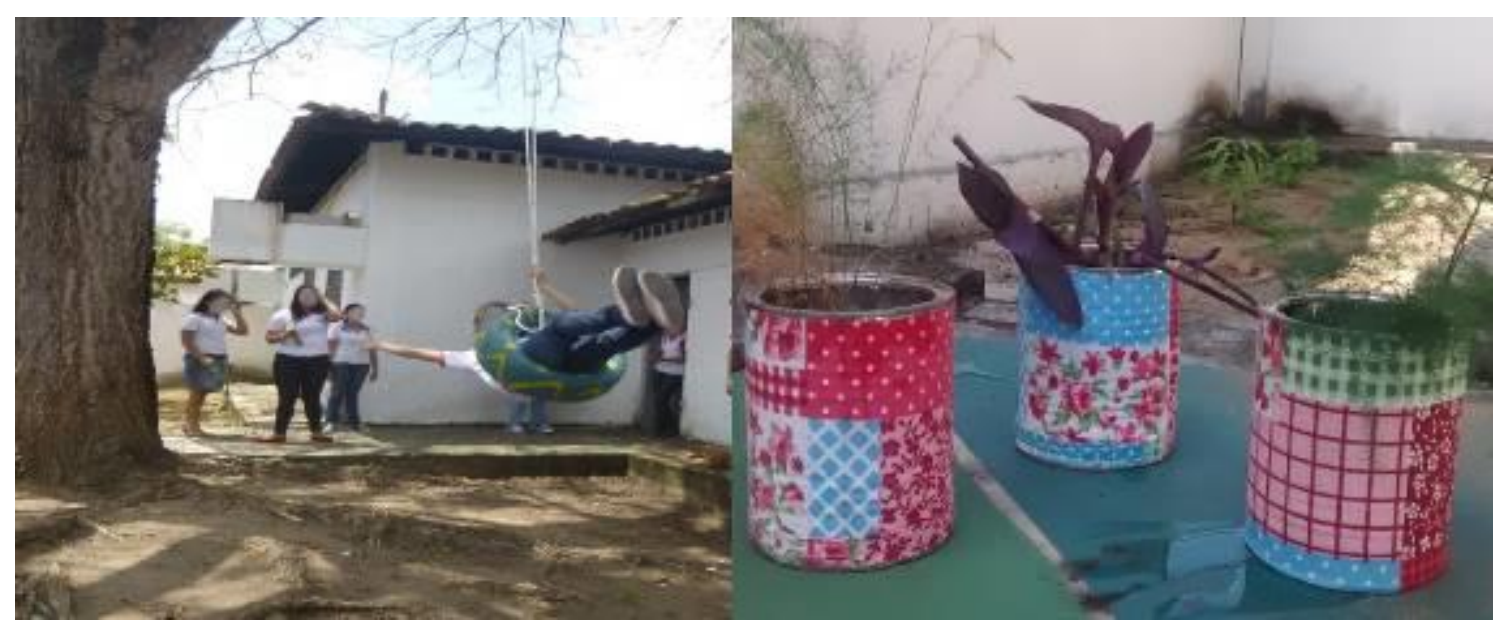

Figura 4: Imagens dos trabalhos de reciclagem realizados pelos alunos. Fonte: Autoria própria.

Apesar dos referidos resultados positivos, em 2015 a escola passou por um período de paralisação, em função da greve dos professores, e logo após o retorno das aulas surgiram casos do Zika Vírus entre professores, alunos e funcionários. O desconhecimento sobre a doença e seus sintomas aparentemente leves, inicialmente, não causou muita preocupação, apenas foi determinado a necessidade dos professores reforçarem, mais uma vez, em sala de aula a importância de manter o ambiente escolar salubre. No entanto, o surgimento de outras doenças relacionadas ao vírus, como a microcefalia e a síndrome de Guillain-Barré, deixou a comunidade escolar em alerta.

Dessa forma, foi necessário entrar em contato com a Secretaria de Saúde para uma vistoria de urgência na escola, sobretudo, diante da presença de alunas grávidas. Segundo o técnico encaminhado, "Até a estrutura antiga da escola favorece espaços para acúmulo de água, o que dificulta o controle da reprodução do mosquito". Esse contexto, chamou atenção para a necessidade da execução de obras de infraestrutura na escola, que vão além das contribuições realizadas mediante a interação dos alunos com a professora. Tal reincidência também requer reflexão e diálogos constantes, a fim de evitar sentimentos negativos sobre as ações desenvolvidas, bem como, criar elos com novos atores para solucionar a problemática.

\section{Considerações Finais}

Apesar do projeto envolver atividades que fazem parte da realidade de muitas escolas, destaca-se a interdisciplinaridade como diferencial, pois foi através das disciplinas referentes aos conteúdos específicos do Curso de Técnico em Eventos, em 2013 Segurança e Higiene no Trabalho e em 2014 Decoração, que as atividades foram desenvolvidas com plena continuidade. Esse fato comprova que a EA pode ser trabalhada em todas as áreas de conhecimentos, níveis de ensino e componentes curriculares e torna o projeto em consonância com a Lei $n^{\circ}$ 9.795/99, que dispõe sobre a Educação 
Ambiental e institui a Política Nacional de Educação Ambiental, propondo que EA não seja uma disciplina específica, já que o principal objetivo é a formação humana para plena prática social de valores, cuidado, respeito, ética e justiça ambiental, isto é, a preparação do indivíduo para o exercício da cidadania (MEC, 2012).

A proposta de conciliar a temática saúde e meio ambiente, através da EA na escola, apresenta-se como uma importante perspectiva para encorajar a análise dos problemas socioambientais existentes, estimular práticas e atitudes mais éticas, e possibilitar o desenvolvimento de atividades que resgatem 0 patrimônio ambiental e incentivem a preservação. A revitalização do "Quadrado" foi um exemplo, pois representou a ampliação do trabalho coletivo realizado nos mutirões de limpeza, a fim de construir espaço para novos conhecimentos e para práticas sociais transformadoras. Além de incentivar relações de troca e de coletividade, estimular o empoderamento e o repensar da função da escola.

Espera-se a continuidade do projeto e o envolvimento de novos atores na busca de solucionar a problemática de reprodução do mosquito transmissor de doenças; que a problemática ambiental referente à questão sanitária na escola - lixo, sujeira e poluição - seja minimizada para prosseguir com o desenvolvimento de outras ações que contemplem a perspectiva ambiental a partir de novos diálogos; e que este artigo, incentive novas reflexões sobre práticas educativas que atentam para a interdisciplinaridade das questões ambientais, como forma de vislumbrar a tomada de consciência a respeito das dificuldades vivenciadas na escola e na forma como a sociedade se relaciona com a natureza.

\section{Referências}

BRASIL, Ministério da Educação. Proposta de Diretrizes Curriculares Nacionais para a Educação Ambiental. Resolução № 2 de Junho de 2012. Disponível em: < http://portal.mec.gov.br/dmdocuments/publicacao13.pdf> Acesso em: 16 de jul. de 2016.

BRASIL, Ministério da Educação. Parâmetros Curriculares Nacionais: meio ambiente e saúde. Brasília: MEC, 1997, V.9.

BRASIL, Ministério do Meio Ambiente. GEO Brasil 2002: Perspectivas do Meio Ambiente no Brasil. Edições IBAMA, 2002. Disponível em: <http://www.ibama. gov.br/sophia/cnia/site cnia/geo brasil 2002.pdf> Acesso em: 03 jul. 2016.

CARVALHO, I.C. . Educação Ambiental: a formação de sujeitos ecológicos. São Paulo: Cortez. 2012.

FERREIRA, C.E.A. O meio ambiente na prática de escolas públicas da rede estadual de São Paulo: intenções e possibilidades. Ambiente \& Educação. Revista de Educação Ambiental. Vol. 18(1), 2013. p. 185- 209. Disponível em: < https://www.seer.furg.br/ambeduc/article/view/3100/2408 > Acesso em: 07 de jul. de 2016.

revista brasileira educação ambiental 
FRANCO, M.I.G.C. Educação Ambiental e metodologias colaborativas: a ressignificação das subjetividades individuais e coletivas em práticas educativas reflexivas. Anais. V Encontro Nacional da Anppas. Florianópolis, SC, 2010. Disponível em: < http://www.anppas.org.br/ encontro5/cd/artigos /GT6-191-853-20100903134653.pdf> Acesso em: 12 mar. 2017.

GROHE, S. L. S.; CORRÊA, L. B. Ressignificando o espaço escolar: uma proposta de Educação Ambiental. Revista Eletrônica do Mestrado em Educação Ambiental. Universidade Federal do Rio Grande. 2012. p. 403-418. Disponível em: < https://www.seer.furg.br/remea/article/view/3167> Acesso em: 01 maio 2016.

GRYNSZPAN, D. Educação em saúde e Educação Ambiental: uma experiência integradora. Caderno Saúde Pública. Rio de Janeiro, 1999. p. 133-138. Disponível em: < https://www.nescon.medicina.ufmg.br/biblioteca/imagem/ 0522.pdf> Acesso em 05 mar. 2016.

GUIMARÃES, M. Educação Ambiental crítica. In: MINISTÉRIO DO MEIO AMBIENTE. Identidades da Educação Ambiental brasileira. Brasilía: Edições MMA. 2004. p. 25-34.

KINDEL, E.A.I. Educação Ambiental nos PCN. In: LISBOA, C. P.; KINDEL, E. A. I. Educação Ambiental: da teoria à prática. Porto Alegre: Mediação, 2012. p.21-28

LIMA, G.F.C. "Crise ambiental, educação e cidadania: os desafios da sustentabilidade emancipatória". In: LAYRARGUES, P.P.; CASTRO, R.S.; LOUREIRO, C.F.B. (orgs.). Educação Ambiental: repensando o espaço da cidadania, São Paulo: Cortez. 2002.

LINDNER, E.L. Refletindo sobre o ambiente. In: LISBOA, C.P.; KINDEL, E.A.I. Educação Ambiental: da teoria à pratica. Porto Alegre: Mediação, 2012. p.1319

LOUREIRO, C.F.B. Pesquisa-ação participante e Educação Ambiental: uma abordagem dialética e emancipatória. In: TOZONI-REIS, M.D.C. (Org) A pesquisa-ação-participativa em Educação Ambiental: reflexões teóricas. Botucatu: Fundibio, 2007. p. 13-119.

MENEGUZZO, I. S.; MENEGUZZO, P. M. Educação Ambiental: possibilidades e desafios no processo de ensino aprendizagem da geografia escolar. Revista Brasileira de Educação Ambiental. Rio Grande, v. 8, 2013. p. 10-19. Disponível em: < http://www.sbecotur.org.br/revbea/index.php/revbea/article/ view/2622/2610> Acesso em: 09 jul. 2016.

MOHR, A.; SCHALL, V.T. Rumos da educação em saúde no Brasil e sua relação com a Educação Ambiental. Caderno Saúde Pública: Rio de Janeiro, 1991. p. 199-203. Disponível em: < http://www.scielo.br/scielo.php?script= sci arttext\&pid=S0102-311X1992000200012> Acesso em: 26 mar. 2016. 
OLIVEIRA, W.F; PIROLA, J. C.; PEREIRA, J. L. G.; 2001. A relação da sáude com a qualidade do ambiente antrópico: uma questão de debate. Revista Brasileira de Educação Ambiental. 2001. p. 20-27.Disponível em: <http://www.sbecotur.org.br/revbea/index.php/revbea/article/viewFile/2021/1038>

Acesso em: 26 mar. 2016.

PORTO, M.F.S. Saúde pública e (in)justiça ambiental no Brasil. In: ACSELRAD, H.; HERCULANO, S.; PÁDUA, J. A. (Orgs.). Justiça ambiental e cidadania. Rio de Janeiro: Relume Dumará: Fundação Ford. 2004. p. 119-140.

RATTNER, H. Meio ambiente, saúde e desenvolvimento sustentável. Revista Espaço Acadêmico. Vol. 9, n. 106, 2010. p. 91-101. Disponível em: <http:// www.periodicos.uem.br/ojs/index.php/EspacoAcademico/article/view/7948> Acesso em: 05 mai. 2016.

REIGADA, C.; TOZONI-REIS, M.F.Q.T. Educação Ambiental para crianças no ambiente urbano: uma proposta de pesquisa-ação. Ciência e Educação (Bauru), v. 10. Bauru, 2004. Disponível em: < http://www.scielo.br/scielo.php? script=sci arttext\&pid=S1516-73132004000200001 > Acesso em: 13 mar. 2017.

RHEINHEIMER, C.G.; GUERRA, T. Processo grupal, pesquisa-açãoparticipava e Educação Ambiental: uma parceria que deu certo. Revista Eletrônica do Mestrado em Educação Ambiental. v.22, 2009. Disponível em: $<$ https://www.seer.furg.br/remea/article/view/2842>Acesso em: 13 mar. 2017.

SEGURA, D.S.B. Educação Ambiental na escola pública: da curiosidade ingênua à consciência crítica. São Paulo: Annablume: Fapesp. 2001.

TOLEDO, R. F; GIATTI, L. L; JACOBI, P. R. A pesquisa-ação em estudos interdisciplinares: análise de critérios que só a prática pode revelar. Interface (Botucatu). vol.18, n.51, 2014. Disponível em: < http://www.scielo.br /scielo.php?pid=S1414-32832014000400633\&script=sci abstract\&tlng=pt>

Acesso em: 08 mar. 2017.

TORALES, M. A. A inserção da Educação Ambiental nos currículos escolares e o papel dos professores: da ação escolar a ação educativo-comunitária como compromisso político-ideológico. Revista Eletrônica do Mestrado em Educação Ambiental. Universidade Federal do Rio Grande. 2013. p. 1-17. Disponível em: < http://www.seer.furg.br/remea/article/view/3437/2064> Acesso em: 03 mai. 2016.

VIERA, A. C. P.; OLIVEIRA, S. S. Educação Ambiental e saúde pública. Vol. 16. 2011. p. 37-44. Disponível em: <http://www.seer.furg.br/ambeduc/ article/viewFile/1025/1197> Acesso em: 01 mar. 2016. 